\title{
Thermal and Skin Condition in Scottish Care Homes in Heating Seasons
}

\author{
Fan Wang ${ }^{1 *}$, Yi Jin ${ }^{2}$, Megan Carpenter ${ }^{1}$, Rebecca Olej $^{3}$, Sarah Payne $^{1}$ \\ 1 School of Energy, Geosciences, Infrastructure and Society, Heriot-Watt University, UK \\ 2 School of Civil Engineering, Architecture and Environment, Xihua University, China \\ 3 Buro Happold, 57-59 Bread Street Edinburgh EH3 9AH
}

\begin{abstract}
The care residents suffer most of the winter dry, but there is a lack of specific standard or building regulation to guide the design and operation in the buildings that can avoid winter dry issue. To develop such a guide would need many evidence-based data, which is not readily available to this group of people. Collecting such data would rely on a specially designed and validated procedure. This study aims to develop and validate such a procedure that allows data to be collected in a real living environment to assess the effect of the room hygrothermal condition on the occupants' skin condition and thermal comfort. The main effort is to minimize the disturbance to the subjects' living and to carry out the data collection in a friendly and easy-understanding way.
\end{abstract}

Peer-review under the responsibility of the organizing committee of the ICMB21.

Keywords: thermal comfort, humidity comfort, skin condition, real living environment

\section{Introduction}

Low indoor humidity is common in heated buildings in winter, but its effect on older occupants' health and comfort is normally overlooked in indoor environment study as major attention was paid to the issues of high humidity such as lack of ventilation, mould proliferation and other related health consequences [1-3]. This study aims to develop and validate such a procedure that allows data to be collected in a real living environment to understand older occupants' comfort and skin condition in a typical heating season. To obtain the most realistic situations in buildings and minimize the possibility of uneasiness of the occupants taking part in the survey, the study was carried out in the participants' real living environment.

\section{Methodology}

Seven residents aged from 78 to 98 years old in a Scottish care home voluntarily participated in the research from January 27 to February 28 in 2020. Their living room, which is approximately 14-16 $\mathrm{m}^{2}$ in size, was selected for data collection. Temperature and humidity in the selected rooms were measured by the Tinytag Ultra 2 TUG-4500 logger. Each logger was installed at $1.5 \mathrm{~m}$ in height and set to log data every 10 minutes. Two skin condition variables, Transepidermal Water Loss (TEWL) and Stratum Corneum Hydration (SCH), of the distal right volar forearm, were measured to assess skin condition. TEWL is universally used for skin condition assessment as its measurement is straightforward, non-invasive and economical $[4,5]$, and its average value on the distal right volar forearm is 7.3-11.8 g. $\mathrm{m}^{-2} \cdot \mathrm{h}^{-1}[6] . \mathrm{SCH}$ is the moisture content in the outermost layer of the skin [7]. $\mathrm{SCH}$ values below 35 a.u. denote for very dry skin, between 35-50 a.u. denote for dry skin, and over 50 a.u denote for a well-hydrated condition [8]. TEWL was measured by the Tewameter TM 300, while the SCH was measured by the Corneometer CM 825. A questionnaire survey on the participants' subjective thermal and humidity comfort carried out in parallel with the skin measurements. The questionnaire was based on the ISO 10551 [9] and ASHRAE Standard 55 [11], and the questions on humidity comfort were designed based on relevant studies $[10,11]$.

The measurements were carried out in four periods to cover a range of humidity levels that are likely to be found in a typical heated environment in winter. In the first period, no humidity intervention was applied. In the second period, humidity intervention was applied at the target humidification level of $40 \% \mathrm{RH}$. In the third period, the humidity intervention stopped. In the fourth period, humidity intervention was applied again at the target humidification level of $50 \% \mathrm{RH}$. The humidity intervention was applied by the Prem-I-Air Sonico, which worked 24 hours a day during the humidity intervened periods.

Two visits were taken in every period at three- or four-days interval to each participant for the skin measurements and questionnaire survey. The participants were required to stay in their room at least two hours before the visit to make sure they and their skin have adapted to the room environment. The participants were required to be sitting at ease (metabolic rate 1.0met) and were in an ordinary winter ensemble (clothing insulation 1.60clo) during the measurements.

\footnotetext{
* Corresponding author.
} 


\section{Results and Discussions}

Figure 1 shows the average room temperature during the whole research and average room RH during the humidity non-intervened period. During the research, the average room temperature was $20.7 \pm 0.5^{\circ} \mathrm{C}$, which was stable and slightly lower than the $21-23^{\circ} \mathrm{C}$ thermal comfort zone [13]. The average room RH during the humidity non-intervened the period was $43.0 \pm 3.9 \%$ and reached the minimum acceptable humidity level [13].

Figure 2 (a) shows the relationship between the TSV, PMV and room temperature. Both the TSV and PMV were significantly correlated with the room temperature $(\mathrm{P}<0.05$, $\mathrm{r}=0.39 ; \mathrm{P}<0.001, \mathrm{r}=0.99)$. According to the regression lines, the neutral temperature of the participants could be calculated, which were $20.8^{\circ} \mathrm{C}$ by the TSV and $19.2^{\circ} \mathrm{C}$ by the PMV. The result suggests that the neutral temperature produced by the PMV method was slightly lower than that produced by the TSV method, which may be low for older people. Figure 2. (b) shows the relationship between the humidity sensation and room RH. The humidity sensation

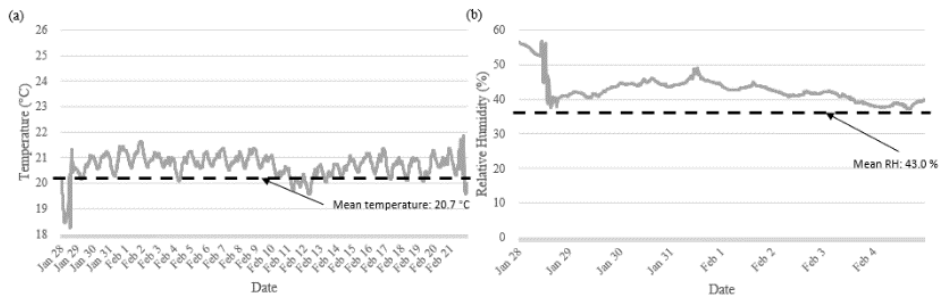

Figure 1 Thermal and humidity condition in the measured rooms. (a) average room temperature during the whole research (b) average room $\mathrm{RH}$ during the humidity nonintervened period.

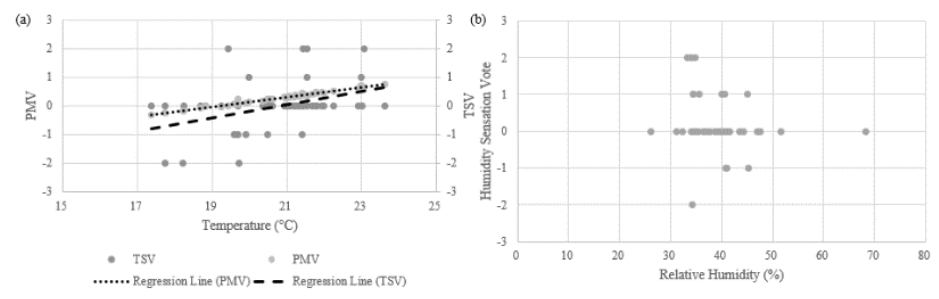

Figure 2 Relationship between the thermal and humidity environment and subjective comfort. (a) room temperature vs PMV and TSV (b) room RH vs humidity sensation. was not significantly correlated with the room $\mathrm{RH}$, which suggests the older participants were not sensitive to the humidity changes and could not give feedback about the room humidity through a questionnaire survey.

Figure 3 shows the percentage of the participants in different types of skin conditions according to the measured TEWL and SCH. The results show that the participants' skin presented an unhealthy skin condition in $76.3 \%$ of the TEWL measurements and a dry or very dry skin condition in $78.6 \%$ of the SCH measurements. The results suggest that most of the participants were suffering unhealthy or dry skin during the research.

(b)

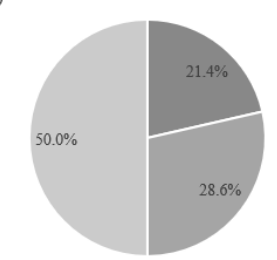

- Unhealthy skin condition "Healthy skin condition = Very dry skin " Dry skin = Well-hydrated skin Figure 3 Percentage of participants suffering from an unhealthy or dry skin condition. (a) skin conditions based on TEWL (b) skin conditions based on $\mathrm{SCH}$.

\section{Conclusion}

This study suggests that the neutral temperature produced by the PMV method was slightly lower than that produced by the TSV method, which may be low for older people. Older people seem not sensitive to humidity changes, and their humidity sensation could not investigate through a questionnaire survey. According to the measured skin variables, unhealthy or dry skin happens normally on older people during the heating seasons even the room average RH was in the humidity acceptable range, suggesting concerns and efforts should be made to keep older occupants' skin healthy in winter.

\footnotetext{
References

1. Krieger J, Higgins D. Housing and health: Time again for public health action. American Journal of Public Health. 2002:758-68.

2. Baughman A, Arens EA. Indoor Humidity and Human Health--Part I: Literature Review of Health Effects of Humidity-Influenced Indoor Pollutants. 1996.

3. Quinn A, Shaman J. Indoor temperature and humidity in New York City apartments during winter. Science of The Total Environment. 2017;583:29-35.

4. Hadgraft J, Lane ME. Transepidermal Water Loss and Skin Site: A hypothesis. International Journal of Pharmaceutics. 2009;373(1):1-3.

5. Darlenski R, Sassning S, Tsankov N, Fluhr JW. Non-invasive in Vivo Methods for Investigation of the Skin Barrier Physical Properties. European Journal of Pharmaceutics and Biopharmaceutics. 2009;72(2):295-303.

6. Kottner J, Lichterfeld A, Blume-Prytavi U. Transepidermal water loss in young and aged healthy humans: a systematic review and meta-analysis. Archives of Dermatological Research. 2013;305:315-23.

7. Berardesca E, Maibach H, Wilhelm K. Non Invasive Diagnostic Techniques in Clinical Dermatology. Berlin: Springer; 2014

8. Heinrich U, Koop U, et al. Multicentre comparison of skin hydration in terms of physical-, physiological- and product-dependent parameters by the capacitive method (Corneometer CM 825). International Journal of Cosmetic Science. 2003;25:45-53.

9. ISO. ISO 10551:2001 - Ergonomics of the physical environment - Subjective judgement scales for assessing physical environments. London: British Standards Institution; 2001.

10. ASHRAE. ASHRAE Standard 55 - Thermal Environmental Conditions for Human Occupancy. Atlanta: American Society of Heating Refrigeration and AirConditioning Engineers; 2017.

11. Nicol F, McCartney K. Final Report (Public) Smart Controls and Thermal Comfort (SCATs): Report to the European Commission of the Smart Controls and Thermal Comfort Project (Contract JOE3-CT97-0066). Oxford: Oxford Brooks University; 2001.

12. Sunwoo Y, Chou C, Takeshita J, Murakami M, Tochihara Y. Physiological and subjective responses to low relative humidity in young and elderly men. Journal of Physiological Anthropology. 2006;25(3):229-38.

13. CIBSE. CIBSE Guide A: Environmental design. London: Chartered Institution of Building Services Engineers; 2017.
} 